\title{
Distribution of Pore Pressure Gradient for Some Deep Formations in Iraqi Oil Fields
}

\author{
Dr. Kareem A. Alwan**, Dr. Faleh H. M. Almahdawi*, Ahmed K. H. Alhusseini** \\ *Petroleum Engineer Department, University of Baghdad \\ ** Petroleum Research and Development Centre
}

\section{Abstract}

Pore pressures are the fluid pressures in the pore spaces in the porous formations. Interactive Petrophysic (IP) software is used to determine the pore pressure gradient from log data. These data are (GR log, Bulk Density and Sonic log).

Surfer software is used to create the formation pressure distribution maps. These maps show the pore pressure gradient (PPG) for sex formations in contour forms. The formations are chosen depending upon the availability of formation in 11wells/11 fields. These maps are provided the pore pressure distribution in middle and south of Iraq and eventually, give a clear imagination for high and low pressure regions for each formation separately.

Six formation are considered in this research, these formations which existed in early Cretaceous and late Jurassic (deep formations) are Shuaiba, Zubair, Ratawi, Yammama, Sulaiy and Gotnia.

Finally, the outputs of these software helps to explain the abnormal pressure location and their distribution for the formation under study, this assists to expected the drilling mud program for these formation.

Keywords: Pore pressures, distribution maps, Shuaiba, Zubair, Ratawi, Yammama, Sulaiy and Gotnia, contour maps 


\section{Introduction}

Pore pressure gradient is considered one of the most important parameters for drilling plan and for geological analyses. Actually, Pore pressures are the fluid pressures in the pore spaces in the porous formations. Pore pressure varies from normal pore pressure, to abnormal pore pressure when it is lower or higher than the hydrostatic pressure (normal pore pressure). The pore pressure gradient is more widely used in drilling calculations, because the gradients are more suitable in order to be used for computation of mud weight (or mud density). The pore pressure gradient can be determined by dividing the pore pressure at a given depth by the true vertical depth [1]. In fact, the mud density should be appropriately selected depending upon pore pressure gradient, wellbore stability and fracture gradient prior to setting and cementing a casing. The drilling fluid is used as a mud pressure to support the wellbore walls in order to preventing influx and wellbore collapse during drilling [2]. To avoid fluid influx, kicks and wellbore instability in an open hole section, a heavier mud pressure than the pore pressure is needed.

However, when mud weight is higher than the fracture gradient of the drilling section, it may fracture the formation, causing mud losses or even lost circulation. To prevent wellbore from hydraulic fracturing by the high mud weight, as needed where there is overpressure, casing needs to be set to protect the overlying formations from fracturing. Pressure gradients and mud weight are expressed in the metric unit, g/cm3 (also called specific gravity or SG)[1] .

\section{$\underline{\text { Result and Discussions }}$}

In IP software, shale normal compaction trend (NCT) lines are created for each input curve (sonic and resistivity logs). The NCT line is used to determine a pore pressure and pore pressure gradient, using overburden gradient (OBGrad) curve as input data [3]. The Eaton [3, 4, $5,6, \& 7]$ relationship for Resistivity $\log (1)$ and sonic $\log (2)$ data are illustrated in equations as below:

$$
\begin{aligned}
& \mathrm{GP}=\mathrm{GOV}-\left(\mathrm{GOV}-\mathrm{GP}_{\mathrm{n}}\right) *\left(\frac{\mathrm{R}_{\mathrm{obs}}}{\mathrm{R}_{\mathrm{nor}}}\right)^{1.2} . \\
& \mathrm{GP}=\mathrm{GOV}-\left(\mathrm{GOV}-\mathrm{GP}_{\mathrm{n}}\right) *\left(\frac{\Delta \mathrm{t}_{\mathrm{nor}}}{\Delta \mathrm{t}_{\mathrm{obs}}}\right)^{3.0}
\end{aligned}
$$

The measured of the hydrostatic pressure gradient for fresh water is $(1 \mathrm{gm} / \mathrm{cc})$ which equivalent to $(0.433 \mathrm{psi} / \mathrm{ft})$ and the measured of the hydrostatic pressure gradient for salt saturated water is $(1.074 \mathrm{gm} / \mathrm{cc})$ which equivalent to $(0.465 \mathrm{psi} / \mathrm{ft})$, then all pressures gradient 
between this range $(0.433-0.465)$ is normal. In order to transform the PPG units from $(\mathrm{gm} / \mathrm{cc})$ to (psi/ft) can use equation (3) as shown below.

$$
\text { PPG }(\mathrm{psi} / \mathrm{ft})=0.45(\mathrm{psi} / \mathrm{ft}) * \mathrm{PPG}(\mathrm{gm} / \mathrm{cc})
$$

In this study, the calculations of eleven wells from 11 fields are done by using sonic log as input data, these wells are Ns-1, No-1, R-172, WQ-15, Rt-3, AAm-1, Wk-1, Dn-1, AK-1, KI-1 and Snd-2[8,9,10]. The results of calculations are established and shown in tables(1 to 6 ) for 6 formations (existed in early Cretaceous and late Jurassic).

\begin{tabular}{|c|c|c|c|c|}
\multicolumn{7}{|c}{ Table (1) Shuaiba formation } \\
\hline No & Easting & Northing & PPG & $\begin{array}{c}\text { Well } \\
\text { name }\end{array}$ \\
\hline 1 & 716 & 3535 & 1.2 & no-1 \\
\hline 2 & 725 & 3440 & 1.092 & WQ-15 \\
\hline 3 & 723 & 3394 & 1.2992 & R-172 \\
\hline 4 & 596 & 3465 & 1.11 & Ns-1 \\
\hline 5 & 686 & 3380 & 1.2205 & Rt-3 \\
\hline 6 & 685 & 3303 & 1.0705 & KI-1 \\
\hline 7 & 386 & 3580 & 1.0946 & WK-1 \\
\hline
\end{tabular}

Table (2) Ratawi formation

$\begin{array}{ccccc}\text { No } & \text { Easting } & \text { Northing } & \text { PPG } & \begin{array}{c}\text { Well } \\ \text { name }\end{array} \\ 1 & 716 & 3536 & 1.4 & \text { no-1 } \\ 2 & 725 & 3439 & 1.15 & \text { WQ-15 } \\ 3 & 723 & 3394 & 1.22 & \text { R-172 } \\ 4 & 596 & 3465 & 1.265 & \text { Ns-1 } \\ 5 & 686 & 3380 & 1.29 & \text { Rt-3 } \\ 6 & 685 & 3303 & 1.36 & \text { KI-1 } \\ 7 & 386 & 3580 & 1.096 & \text { WK-1 } \\ 8 & 522 & 3422 & 1.13 & \text { Dn-1 } \\ 9 & 626 & 3234 & 1.06 & \text { AK-1 }\end{array}$

Table(3) Zubair formation

$\begin{array}{ccccc}\text { No } & \text { Easting } & \text { Northing } & \text { PPG } & \text { Well name } \\ 1 & 716 & 3536 & 1.54 & \text { no-1 } \\ 2 & 725 & 3439 & 1.27 & \text { WQ-15 } \\ 3 & 723 & 3394 & 1.22 & \text { R-172 } \\ 4 & 596 & 3465 & 1.48 & \text { Ns-1 } \\ 5 & 686 & 3380 & 1.29 & \text { Rt-3 } \\ 6 & 685 & 3303 & 1.12 & \text { KI-1 } \\ 7 & 386 & 3580 & 1.095 & \text { WK-1 } \\ 8 & 522 & 3422 & 1.38 & \text { Dn-1 } \\ 9 & 787 & 3389 & 1.6 & \text { Snd-2 }\end{array}$




\begin{tabular}{ccccc}
\multicolumn{5}{c}{$\begin{array}{c}\text { Table (4) Yammama } \\
\text { formation }\end{array}$} \\
$\begin{array}{c}\text { No } \\
\text { Easting }\end{array}$ & $\begin{array}{c}\text { Northing } \\
\text { PPG }\end{array}$ & $\begin{array}{c}\text { Well } \\
\text { name }\end{array}$ \\
1 & 716 & 3536 & 1.54 & no-1 \\
2 & 725 & 3439 & 1.65 & WQ-15 \\
3 & 723 & 3394 & 1.2 & R-172 \\
4 & 596 & 3465 & 1.2 & Ns-1 \\
5 & 685 & 3303 & 1.3 & KI-1 \\
6 & 386 & 3580 & 1.13 & WK-1 \\
7 & 522 & 3422 & 1.14 & Dn-1 \\
8 & 626 & 3234 & 1.4 & AK-1
\end{tabular}

Table (5) Sulaiy formation

$\begin{array}{ccccc}\text { No } & \text { Easting } & \text { Northing } & \text { PPG } & \begin{array}{c}\text { Well } \\ \text { name }\end{array} \\ 1 & 716 & 3536 & 1.56 & \text { no-1 } \\ 2 & 725 & 3439 & 1.7 & \text { WQ-15 } \\ 3 & 614 & 3533 & 1.4 & \text { Aam-1 } \\ 4 & 596 & 3465 & 1.6 & \text { Ns-1 } \\ 5 & 685 & 3303 & 1.5 & \text { KI-1 } \\ 6 & 386 & 3580 & 1.13 & \text { WK-1 } \\ 7 & 522 & 3422 & 1.06 & \text { Dn-1 } \\ 8 & 626 & 3234 & 1.35 & \text { AK-1 }\end{array}$

Table (6) Gotnia formation

$\begin{array}{ccccc}\text { No } & \text { Easting } & \text { Northing } & \text { PPG } & \begin{array}{c}\text { Well } \\ \text { name }\end{array} \\ 1 & 614 & 3533 & 1.36 & \text { Aam-1 } \\ 2 & 596 & 3465 & 1.6 & \text { Ns-1 } \\ 3 & 685 & 3303 & 1.75 & \text { KI-1 } \\ 4 & 386 & 3580 & 1.13 & \text { WK-1 } \\ 5 & 522 & 3422 & 1.132 & \text { Dn-1 }\end{array}$




\section{Formation Pore Pressure Gradient Distribution in Contour Maps}

Formation pressure distribution maps are done using Surfer software. These maps show the pore pressure gradient (PPG) for six formation in contour forms. The pore pressure gradient which used to draw these maps was taken from pore pressure calculations. The formations are chosen depending upon the availability of the formation in 11 wells located in 11 fields. These formations from shallower to deeper are Shuaiba, Zubair, Ratawi, Yammama, Sulaiy and Gotnia.

Two parameters are considered in drawing of these maps:

1-The value of pore pressure gradient (PPG) for every formation.

2-Northing and Easting coordinates.

Maps in figures (1-6), as shown below, are provides the pore pressure distributions in middle and south of Iraq and gives a clear imagination for high and low pressure regions for every formations separately. 


\section{1- Shuaiba Formation}

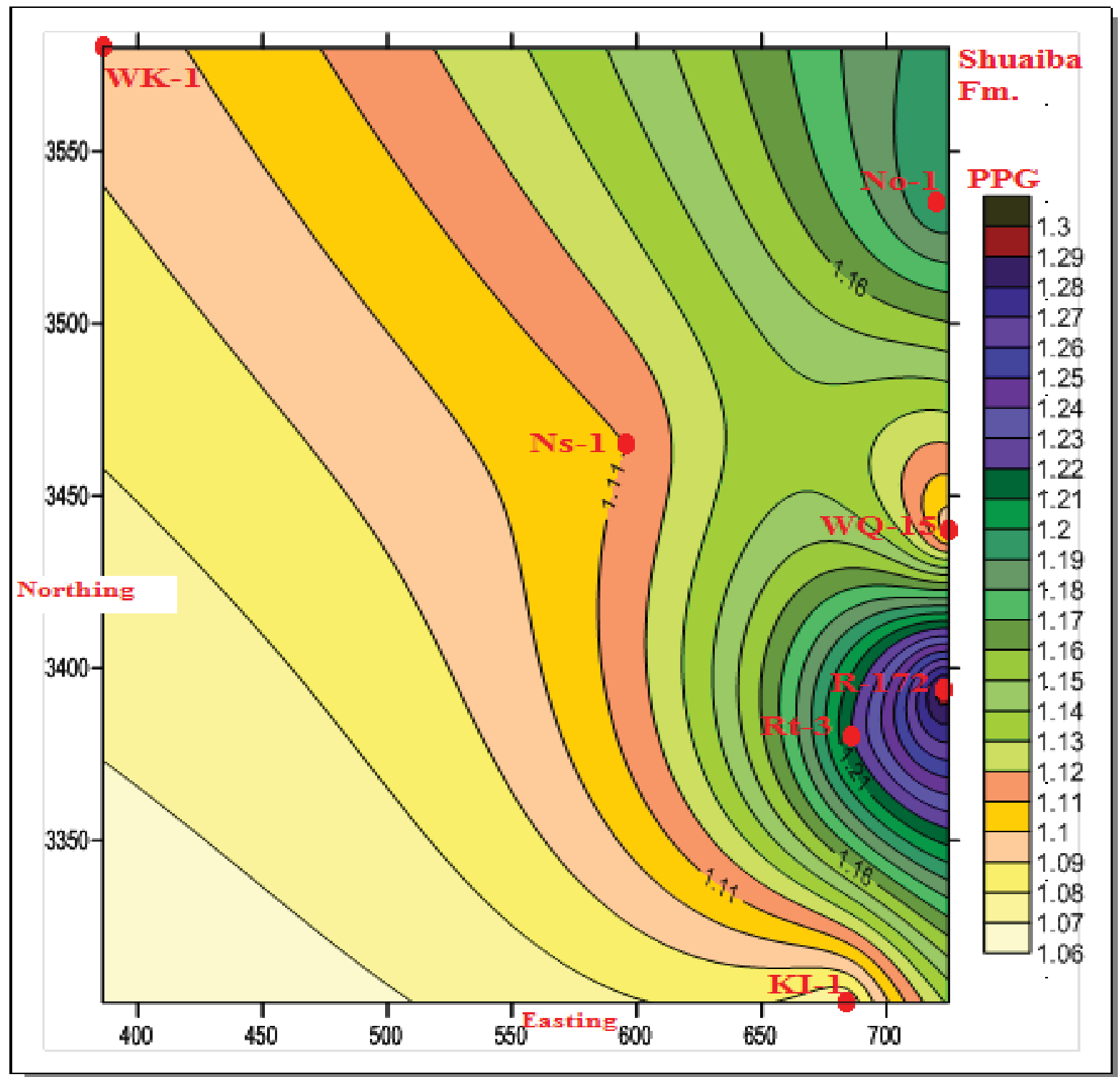

Fig. (1) Formation pore pressure distribution for Shuaiba formation.

As shown in figure (1), Shuaiba formation is Normal to Abnormal Low Pressure. Pore pressure gradient tends to increase from south-west of Iraq where the lower value of PPG especially at KI-1 to south of Iraq where the higher value of PPG at R-172. 


\section{2- Zubair formation}

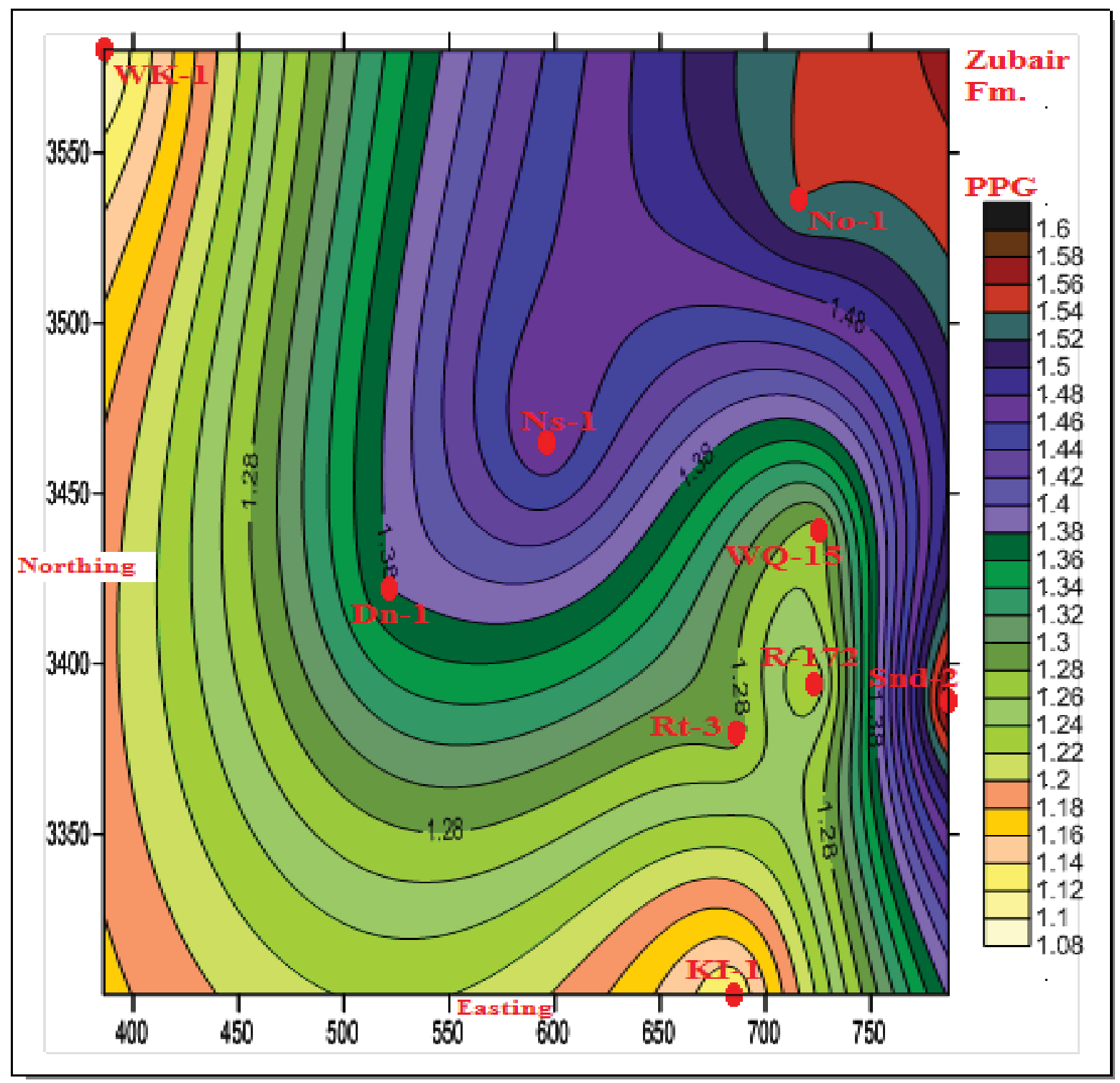

Fig.(2) Formation pore pressure distribution for Zubair formation.

The contour map of Zubair formation figure (2) shows that it is Normal to Abnormal Pressure increasing from west of Iraq where the lower value of PPG especially at WK-1 to East and southeast of Iraq where the higher value of PPG at No-1 and Snd-2. 


\section{3- Ratawi Formation}

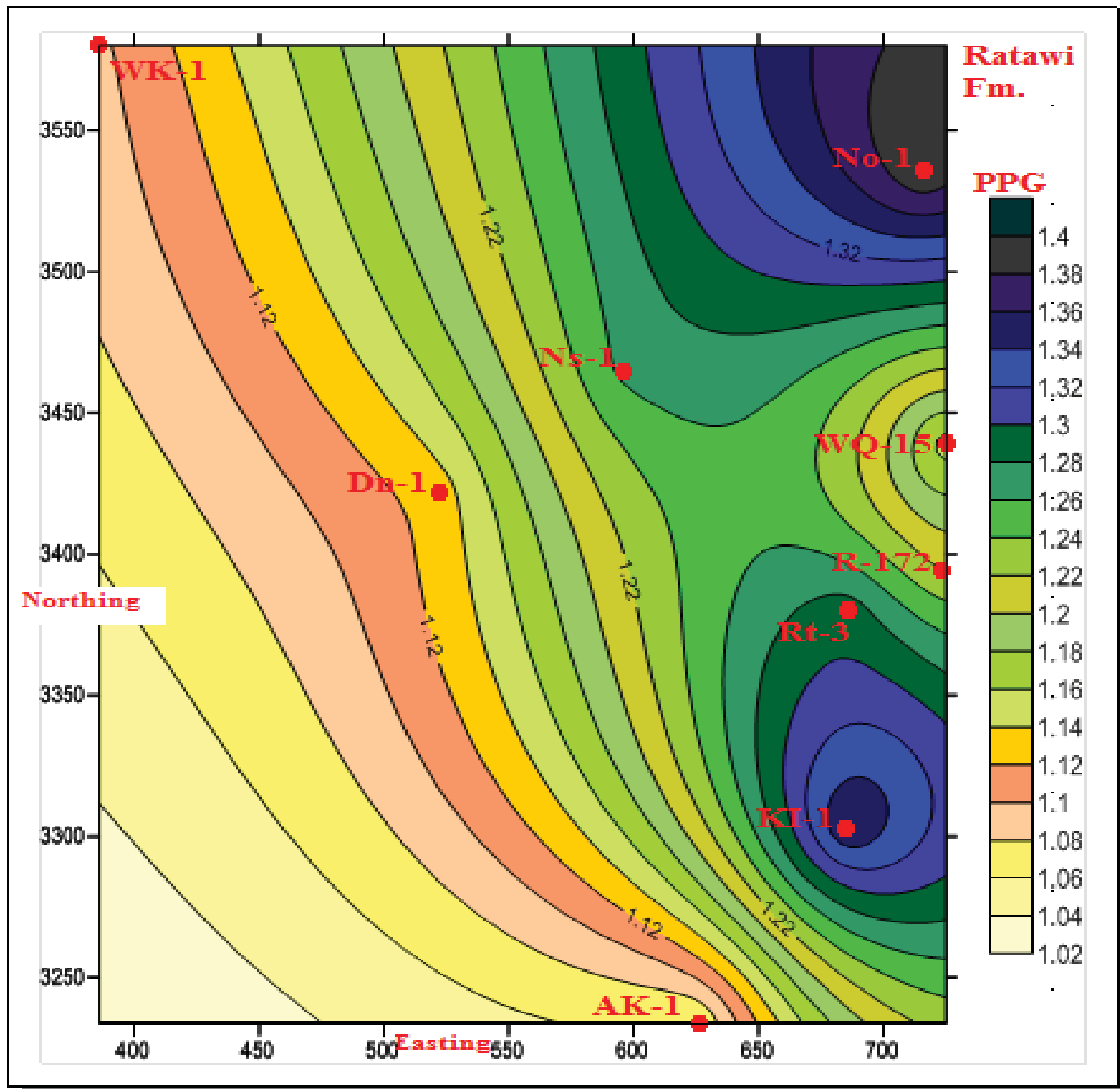

Fig. (3) Formation pore pressure distribution for Ratawi formation.

Ratawi formation is Normal to Abnormal Pressure figure (3) the pore pressure gradient increases from south of Iraq where the lower value of PPG especially at AK-1 to southeast of Iraq where the higher value of PPG at No-1. 


\section{4- Yammama Formation}

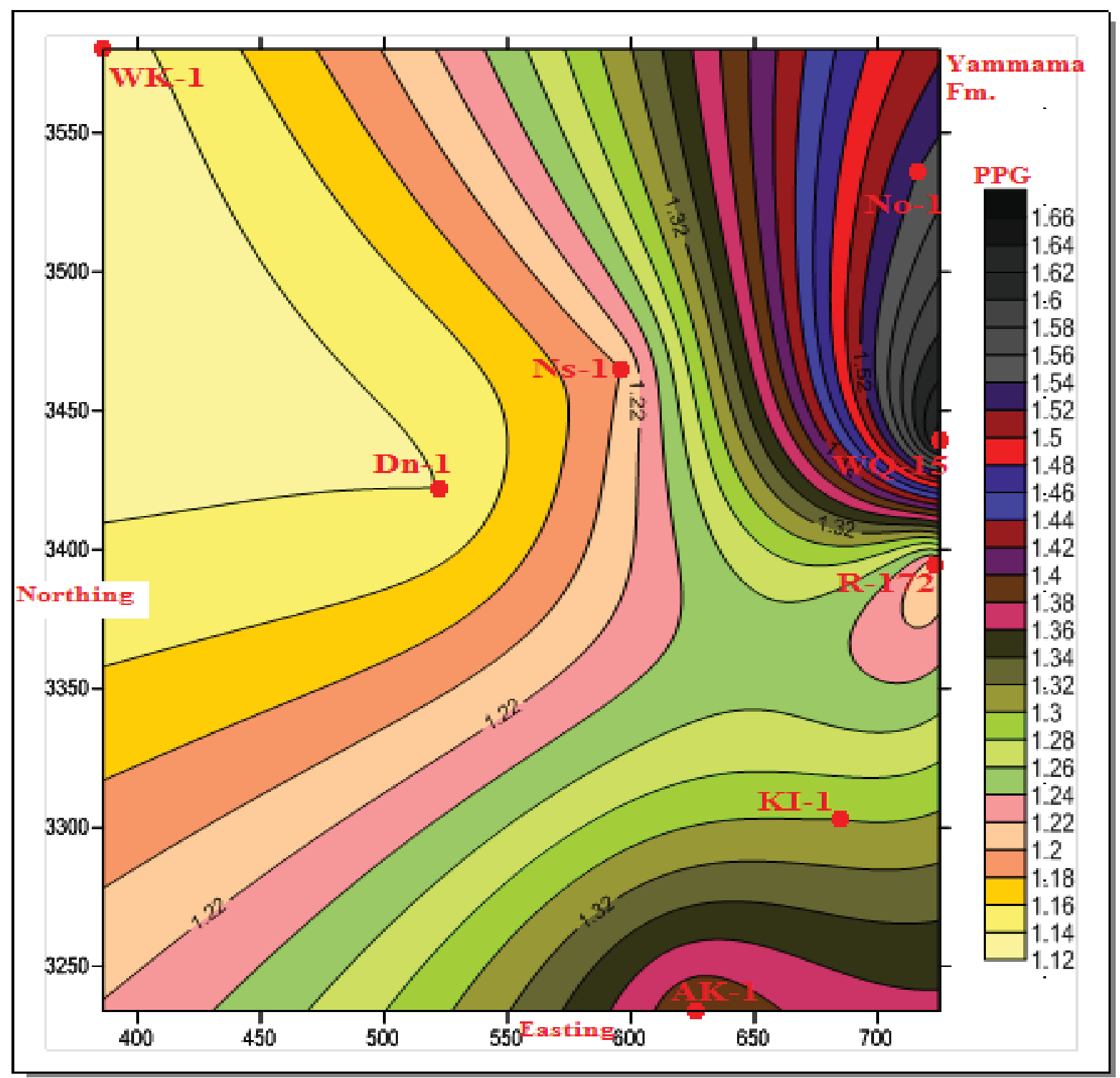

Fig. (4) Formation pore pressure distribution for Yammama formation.

As shown in figure (4), the contour map shows that Yammama formation is Normal to Abnormal high Pressure. Pore pressure gradient tends to increase from west of Iraq where the lower value of PPG especially at WK-1 to south of Iraq where the higher value of PPG at WQ-15. 


\section{1- Sulaiy Formation}

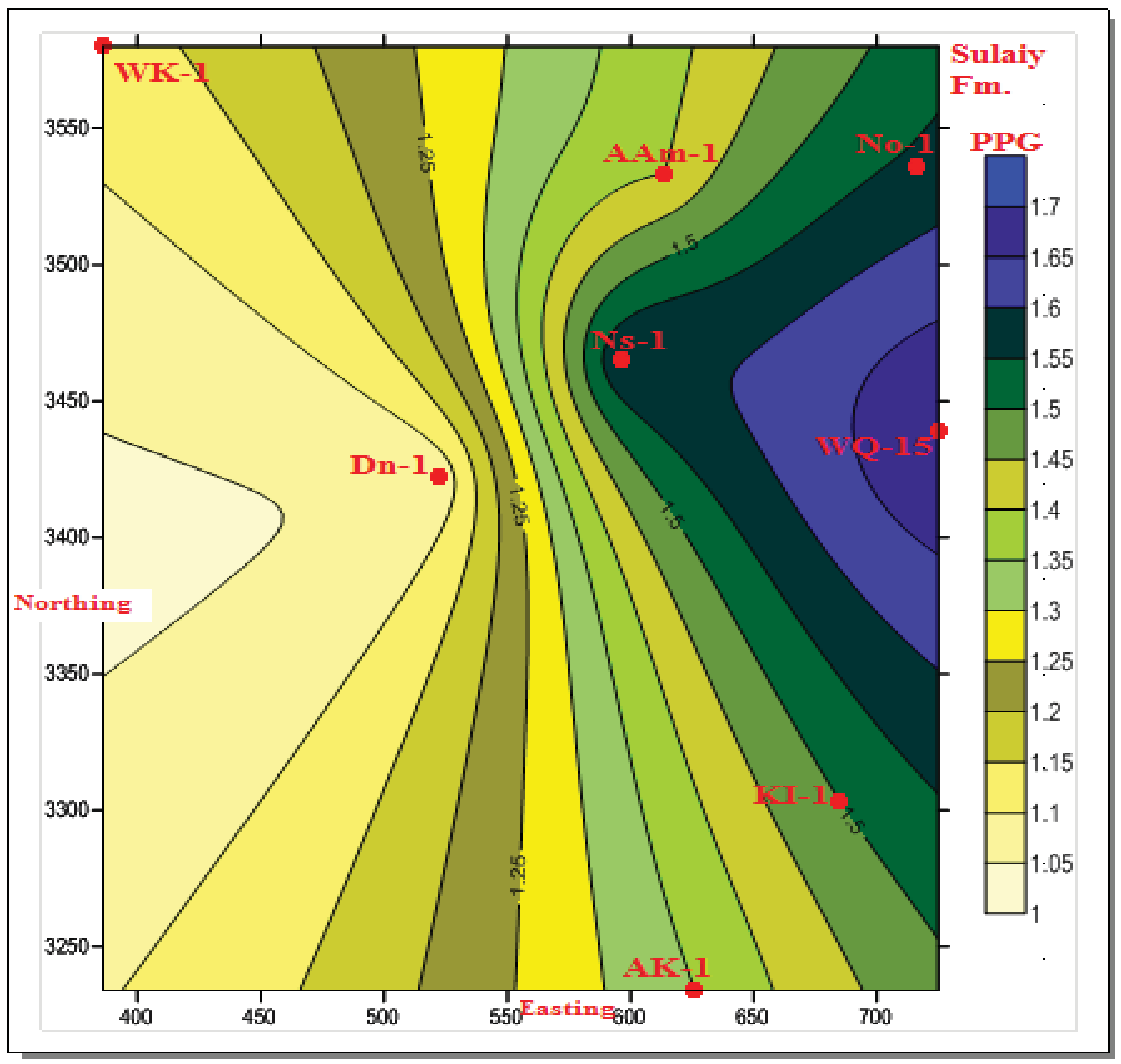

Fig.(5) Formation pore pressure distribution for Sulaiy formation.

Sulaiy formation is Abnormal High Pressure figure (4) the pore pressure gradient increases from west of Iraq where the lower value of PPG especially at WK-1 to south of Iraq where the higher value of PPG at WQ-15. 


\section{2- Gotnia Formation}

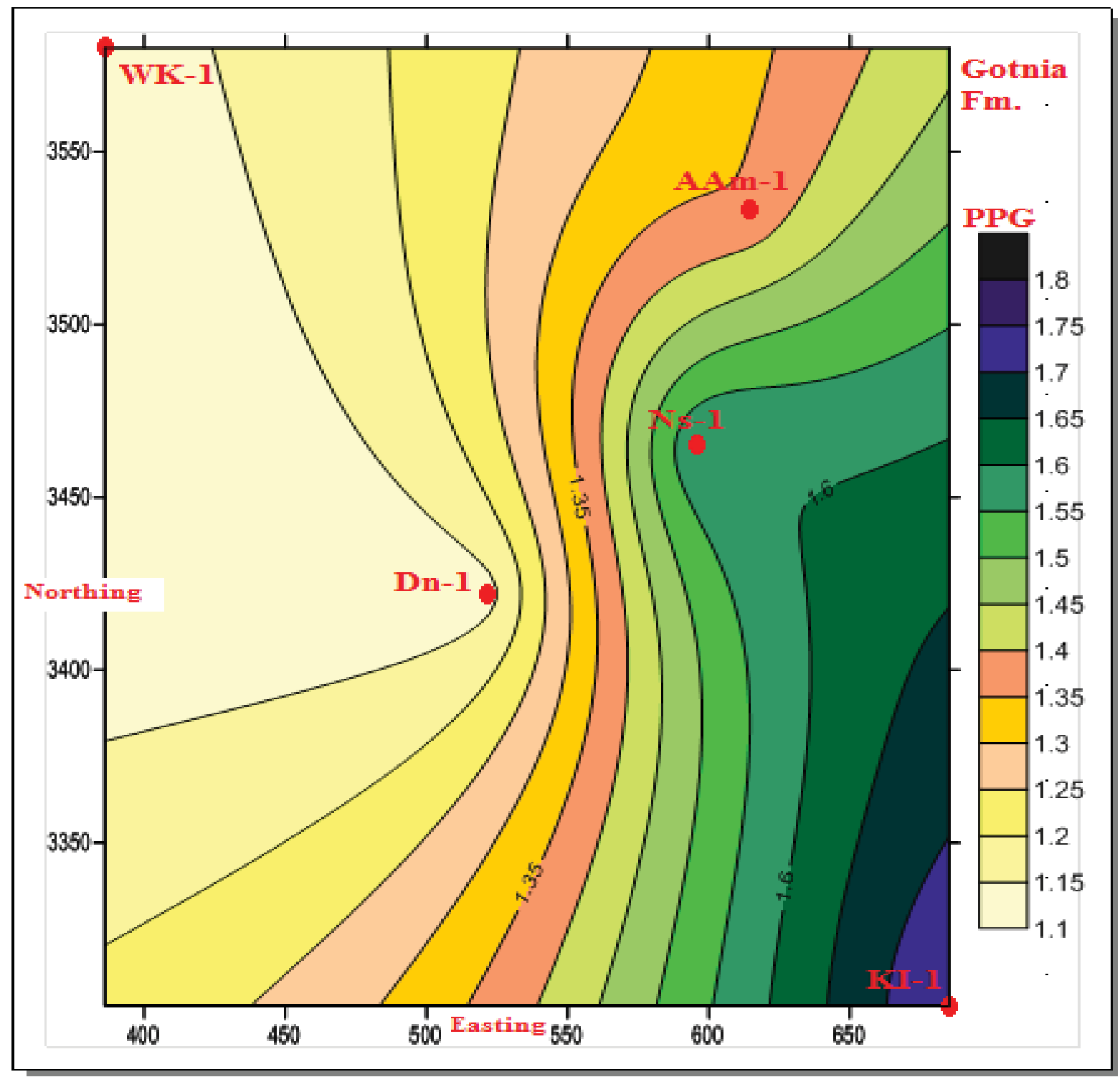

Fig. (6) Formation pore pressure distribution for Gotnia formation.

As shown in figure (6), the contour map shows that Gotnia formation is Abnormal High Pressure. Pore pressure gradient tends to increase from west and southwest of Iraq where the lower value of PPG especially at WK-1 and Dn-1 to south of Iraq where the higher value of PPG at KI-1. 


\section{Conclusions}

Our conclusions from the maps which are created by Surfer software for 6 formations in 11 wells/fields can be shown below:

1. The highest formation value of pore pressure is located in Gotnia formation and Sulaiy formations, especially in south of Iraq such as KI-1 and WQ-15. While the lowest value of pore pressure is located in Hartha formation, especially in southwest of Iraq such as Dn-1.

2. From pore pressure maps concluded:

a- Gotnia formation shows the abnormal high pore pressure at wells KI-1 and Ns-1.

b- Sulaiy formation shows the abnormal high pore pressure at wellsWQ-15, No-1, Ns-1 and KI-1.

c- Yammama formation shows the abnormal pore pressure at wellsNo-1 andWQ-15.

d- Ratawi Formation shows the abnormal pore pressure at wells KI-1, and No-1.

e- Zubair formation shows the high pore pressure atSND-2 and No-1 and low pressure at WK-1 and KI-1.

f- Shuaiba Formation shows the abnormal low pore pressure at wells KI-1, WQ-15 and WK-1.

Results mentioned above are very important in designing drilling and completion programs of the above productive formations.

\section{$\underline{\text { Recommendations }}$}

1) If additional data be available such as resistivity, conductivity data and daily drilling reports, other methods can be used to predict both pore and fracture pressure gradient.

2) It is recommended to insert other wells in western of Iraq to create a clearest idea about pressure behavior in this region.

3) It is recommended to choose deep wells with complete data for all depth to estimate pressure for deeper formations. 


\section{$\underline{\text { References }}$}

1. Zhang, J. "Pore pressure prediction from welllogs: Methods, modifications, and newapproaches", Earth-Science Reviews, 2011-09.

2. Institute of petroleum Eng., "Formation Pressure 5", Heriot Watt University, 2002.

3. Schlumberger, “Interactive Petrophysics Manual”, Senergy Ltd, 2008.

4. Rafiad K. A., "Prediction of Abnormal Formation Pressure in Southern Iraq", A Thesis Submitted to the College of engineering of the University of Baghdad, 1996.

5. Nagham J. A., "A Study of Fracture Pressure Gradient for Deep Wells in southern Iraqi oil fields", A Thesis Submitted to the College of engineering of the university of Baghdad, 2004.

6. Ben A. Eaton, "Graphical Method Predicts Geopressure World Wide", World Oil, July 1976, pp. (100-104).

7. Rakesh R. R. and Dr. C. Chandrashekhar, "Pore Pressure Prediction a case Study in Cambay Basion”, Indian oil Corporation limited, January 2015.

8. Oil Exploration Company, "Final drilling, geological and well reports" 1970-1980.

9. South oil company, "Final drilling, geological and well reports" 1974-2013.

10. Missan oil company, "Final drilling, geological and well reports" 1976-1984. 